\title{
Uncertainty beyond Technology Transfer Sino-Saudi JV Study
}

\author{
Dr. Saleh L. Alghamdi, Phd \\ University of Jeddah, Saudi Arabia
}

\begin{abstract}
On Sino-Saudi joint ventures is to be made with two major implications. The first is a special SinoSaudi partnership, which carries strategic, geopolitical and even military considerations, which is far beyond the pure economic concern. The second is the culture differences between partners, which may create gap to the technology transfer, or enhance the transfer, on different occasions. The culture difference also impacts partners' behavior and their perception to each other, and hence generates different effects on mutual trust, which is an essential element of corporate relationship quality, and in turn the transfer of technology.
\end{abstract}

Keywords: Technology Transfer, Sino-Saudi, Partnership, Uncertainty

\section{INTRODUCTION}

Based on the of lack researches conducted between Sino-Saudi in terms of their relationship, in this study we aimed to focus on the following frame and thinking1: factors affecting knowledge and technology transfer - regulatory role of partnership relation - joint ventures transfer performance. In the following, the research will make a comprehensive utilization and combine the mechanism of the joint ventures knowledge transfer process, implementation mechanism and coordination mechanism to guide the joint ventures performance.

We had conducted a large-scale survey for the joint ventures in China and Saudi Arabia by means of E-view software to perform descriptive statistics, correlation analysis and multiple regression analysis for data. We have also created an empirical perspective to verify the characteristics of the body of knowledge transfer, knowledge transfers partnership relation to the mechanism of the body of knowledge transfer / acquisition, and verify the impact of the knowledge transfer / acquisition on joint ventures transfer performance.

\section{OBJECTIVE}

The purpose of this study is to fill the gap of knowledge transfer in multinational corporations, especially in SSJV part. In the context of differentiated organizational network, this study featured the integration of knowledge, enterprise systems, organizational culture, motivation and organizational characteristics of the transferor and recipient, implication of a partnership in knowledge transfer relationship into a unified framework for both sides in the research, mainly constructing regression models, using reliability analysis, validity analysis, descriptive analysis, correlation analysis and regression analysis has been conducted in order to find statistical analysis on survey data. At the same time, in order to partially offset the impact factors of the defect, this study will be based on knowledge transfer mechanism of the model, focusing on the regulatory role of partnership relation on SSJV's knowledge and technology transfer. Specifically, the study will be based on the theoretical basis of the model from the characteristics of knowledge transferor side, characteristics of knowledge recipient side and relationship between the two sides to build a model of integration.

\section{Partnership Relation between Sino-Saudi}

People's Republic of China and Saudi Arabia established their diplomatic relations on July 21, 19902.

1 Teece, D.J.1977, Technology transfer by multinational firms: The resource costs of transferring technological know-how. Economic Journal, 87(346):242-261.

2Xinhuanet: Saudi Arabia and Chinese Leaders Exchange Congratulatory Messages on the 20th anniversary of establishment of diplomatic relations Web.21 July,2010http://news.xinhuanet.com/politics/2010-07/21/c_13408 769.html 
The diplomatic relations between the two countries has remained peaceful and friendly state, which has created a model of friendly cooperation in two different social systems, beliefs, cultural traditions. With the formation of a global strategic adjustment, the germinal new global order will become an important factor that connects Beijing and Riyadh. China is Saudi Arabia's largest oil buyer. Meanwhile, Saudi Arabia is China's biggest oil supplier. With the global economic growth, this trend will continue. Trade and investment relationship between two sides will become deeper, particularly in the energy and trade cooperation, project contracting, labor cooperation and investment and other fields. As the Chinese Foreign Minister, Wang Yi (2013) said that China and Saudi Arabia were allround strategic partnership ${ }^{3}$. The two countries have grown from the original simple commodity trade relation to cooperating with each other in investment, project contracting, labor and other fields. Project contracting and labor cooperation between the two countries are progressing smoothly. Engineering contracting projects between China and Saudi Arabia were signed in the areas including communication, roads, oil services and drilling. In import and export, China is the most important trading partner of Saudi, trade exchange between the two countries amounted to $\$ 76$ billion $^{4}$.

\section{The Energy Cooperation and Knowledge Technology Transfer between China ANd SAUdi Arabia}

The energy cooperation between China and Saudi Arabia has a solid foundation for the development. In the distant ancient times, China has had contacts with Arabia that located at the intersection of three continents of Asia, Africa and Europe. There are too many historical witnesses since second century BEC. Such as the Silk Road and the Spice Route ${ }^{5}$. At the beginning of twenty-first Century, the successful launch of cooperation forum between China and Saudi Arabia promotes energy cooperation forward. Mutual benefit and win-win attitude results in a strong vitality of the energy cooperation. In order to meet the needs of today's development in the international situation and strategic co-operation, the current energy cooperation extends to the new energy field and promotes the economic and trade cooperation to investment, science, technology, infrastructure, finance and other areas. China and Saudi Arabia confirm the partnership of energy development in a full range.

Chinese Premier declared new energy policy in the World Future Energy Summit held in Abu Dhabi in January 2012.He proposed to put energy efficiency in the first place, develop new and renewable energy, promote the revolution in energy science and technology and ensure the safety of energy. All of this caused people's response and resonance, including a number of state officials and scholars in Arabia $^{6}$. Saudi Arabia's foreign ministry official said: "Premier Wen attended the summit, which fully shows the Chinese government's emphasis on sustainable development and renewable energy. He called on us to carry out more extensive cooperation in the field of renewable energy, which we are very welcome". In the keynote speech at the opening ceremony of the Sixth Ministerial Conference in June 5, 2014, President Xi stressed that "Belt and Road Initiative is a win-win way. Because of the Silk Road plan, Saudi Arabia and China, that starts to communicate. We are natural partners in building 'The Belt and Road'. The two sides should stick to the principles of joint consultation, CO creation, and common enjoyment in order to form a benefit community and a fate community together". Saudi Arabia also endorsed President Xi's views on strengthening the forum construction and the development of bilateral strategic cooperation, supported to build China's Belt and Road Initiative ${ }^{7}$.

\section{KNOWLEDGE AND TECHNOLOGY TRANSFER}

The generation and transfer of knowledge and technology is a very significant source for joint ventures to obtain a sustainable competitive advantage. Teece (1977) proposes that knowledge and

3Xinhuanet: Wang Yi (Chinese Foreign Minister): China and Saudi Arabia are all-round strategic partnership relation. Web.26 Dec,2013.http://www.fmprc.gov.cn/mfa_chn/zyxw_602251/t1112158.shtml

4Cankao News: Saudi Arabia entrepreneurs believe Saudi Arabia trade will exceed \$ 120 billion in five years . Web.13 Mar, 2014. http://finance.cankaoxiaoxi.com/2014/0313/360197.shtml

${ }^{5}$ Pan Guang, Yu Jianhua: "from the Silk Road to Asia Europe Meeting: Asia Europe relations two thousand years", Beijing: Central Party School of the Communist Party of China Press, 2004, 4 8.

${ }^{6}$ Wen: the deepening comprehensive cooperation to achieve common development -- the speech of the Sino Saudi cooperation forum opening theme in the fourth ministerial meeting ", May 132010 ,

${ }^{7}$ XI: "carry forward the spirit of the Silk Road to deepen the cooperation between China and Saudi Arabia, the speech of the Sino Saudi cooperation forum opening theme in the Sixth ministerial meeting " , "people's Daily" June 6. 2014. 
technology transfer could help international enterprises have accumulated valuable knowledge and promote the diffusion of technology, in order to narrow the technology gap between regions. Since then, the researches on knowledge and technology transfer have quickly attracted many scholars and practitioners. From the perspective of the micro, systematic modern technology is mainly reflected in the researches of new technology development, as well as the dependence on personnel, equipment, financial support, and many other factors. Systemic lupus of modern technology determines the increasingly complex of international technology transfer process, showing a significant diversification characteristic. First of all, the systemic lupus of modern technology makes the new technology difficult to split, as well as difficult to adaptively transform. This objectively requires that the introduction side of knowledge and technology must consider all aspects of equipment, software, and human resources in the introduction of new technologies to ensure the introduction of digestion and absorption technology.

Multinational joint ventures play important roles in guiding and distributing to global FDI flows, but it is also the carrier of global knowledge transfer. In the course of business, multinational joint ventures promote technology transfer behavior, movement of persons, cooperative R \& D, management model and the concept of subtle penetration by the way of the contract market, the emergence of the knowledge of external knowledge spillover effects, from the home country to the joint ventures countries ${ }^{8}$. At the same time, Resource-Based View of Penrose (1959) and "Tacit knowledge" concept of Polanyi (1962) further broaden people's horizons. Knowledge, as a resource, can bring benefits for the enterprise.

Knowledge and technology is seen as an important intangible corporate intellectual capital, which is different from the current machinery, land, equipment, cash and other tangible assets in the financial statements. Intellectual capital includes human capital, structural capital and customer capital (Petrash, 1996). These are intangible, which cannot be seen from the financial statements, but it determines the company's potential and future competitive advantage (Edvinson. and Malone, 1997). UNIDO believes that technology is the sum of knowledge, experience and skills for enterprises aiming at manufacturing one or more products (Darr and Kurtzbery, 2000).Different understandings for knowledge is often combined with the classification of knowledge. Some conclusions can be drawn from the current literature that the standard classifications of knowledge for scholars include the following aspects: the role of knowledge and technology, the degree of difficulty to obtain and transfer knowledge, details of the attached carrier. Many scholars may also refer to two or more dimensions when compartmentalizing knowledge and technology. For instance, the classification of knowledge and technology of Hedlund (1994) is a combination of two dimensions: the difficulty degree of acquisition or transfer of knowledge as well as the attached carrier of knowledge.

\section{Gaps of Previous Studies}

With respect to emerging Sino-Saudi partnership in economic, strategic and geopolitical aspects, researchers concentrate on public information about macro events, including large government contracts, state visits, bilateral trading volume and giant joint ventures firms. There is little analysis for the details of various cooperation and their interior microstructures. The reason is that the cooperation lacks sufficient media coverage, and is not considered a broad topic in the academic society. On the other hand, the academic society oversees the microeconomic factors in the cooperation, plus the lack of first hand research data, the information and technology elements are not paid enough attention. Additionally, the interpersonal relationship between individuals from two societies is outside the scope of existing researches. Till now, the role of individual interactions in Sino-Saudi partnership context is yet to be discovered.

\section{KNOWLEDGE BRIDGING}

This study is unique from all previous studies, and creates innovation in several aspects, and discusses intensively in introduction part. First of all, it provided information from all level of SSJV, in comparison, previous researches only focuses in top level decision makings.

8 Van Wijk,R J,JJansen,J.P, and Lyles,M.A.2008,Inter-and Intra-Organizational knowledge transfer: A metaanalytic review and assessment of its antecedents and consequences. Journal of Management Studies,45(4)830853. 
Secondly, according to literature review, there are rare researches dedicated to knowledge transfer in SSJV, and this research is probably the first that provides adequate attention in SSJV, backed up with extensive field data.

Finally, its focus in researching technology transfer is different. Previous researches made attempt to quantify the quality of technology transfers, and use statistical tolls, usually regressions to detect relationship between quality of technology transfer and individual factors. This research focus in trust and culture shocks, which is more difficult to apply quantitative methods.

\section{FINDINGS}

There is a positive correlation between "knowledge and technology transfer performance" and "Parent Company's Transfer Willingness". We also found a positive correlation between "knowledge and technology transfer performance" and "Parent Company's Transfer Willingness". The "partnership" relationship in official level reflected may enhance the technology transfer between Sino-Saudi partners. Knowledge and technology transfer performance is inversely proportional to geography distance. There is a positive correlation between "Knowledge and technology transfer performance" and institutional differences. The relationship embedding knowledge will increase its tacitness, thus reducing knowledge and technology transfer in performance. And finally a positive correlation between "Knowledge and technology transfer performance" and "tacit knowledge and technology" has been found in this study.

\section{RESEARCH LIMITATIONS}

After the induction and summary of the full research, it must be noted that, although the dissertation completed basic idea of the proposed theory, obtained some important and meaningful conclusions, yet due to the constraints of the author's knowledge structure, research conditions and research capabilities and other objective factors, there are still many shortcomings about Sino-Saudi joint ventures knowledge transfer process in the empirical study, which needs improving and deepening in future research.

\section{REFERENCES}

[1] Petrash, G.1996, Doo's Journal to a knowledge value management culture. European Management Journal. 14(4):365,373.

[2] Edvinson. L. and Malone, M.S.1997, Intellectual capital: Realizing your company's true value by finding its hidden brainpower. New York: Harper Business.

[3] Darr.E.D, and Kurtzbery, T.R.2000, An investigation of partner similarity dimensions on knowledge transfer. Organizational Behavior and Human Decision Processes, 82(1):28-44.

[4] Hedlund, G.1994, A mode of knowledge management and the $N$-form Corporation. Strategic Management Journal15 (52):73 - 90.

[5] Teece, D.J.1 977, Technology transfer by multinational firms: The resource costs of transferring technological know-how. Economic Journal, 87(346):242-261.

[6] Simonin, B.L.1997, the importance of developing collaborative know-how: An empirical test of the learning organization. Academy of Management Journal, 40(5):1150-1174.

[7] Polanyi, M.1966, The tacit dimension. Garden City, NY: Doubleday.

\section{AUTHOR's BIOGRAPHY}

My background includes serving as a customer service within call-center. After I got my Master's In Business from Australia I worked for airline company as HR Specialist.

Most recently, I worked as BDM at private company, where my responsibilities included finding foreign investors especially from Far-East Asia, where I have some experience and good connection there.

Last June I got my $\mathrm{PhD}$ in International Business specialized in International Joint Venture. My topic is "A Study on Knowledge and Technology Transfer in International Joint Ventures with Multiple Implications: Insights from Sino-Saudi Joint Ventures in Oil and Petrochemical Industries. 